\title{
Rethinking “Generation Me": A Study of Cohort Effects From 1976-2006
}

Perspectives on Psychological Science 5(I) 58-75

(C) The Author(s) 2010

Reprints and permission: http://www. sagepub.com/journalsPermissions.nav DOI: $10.1177 / 174569 \mid 609356789$

http://pps.sagepub.com

@SAGE

\author{
Kali H. Trzesniewski' and M. Brent Donnellan ${ }^{2}$ \\ 'Department of Psychology, University of Western Ontario, London, Ontario, Canada and ${ }^{2}$ Department of Psychology, \\ Michigan State University, East Lansing, MI
}

\begin{abstract}
Social commentators have argued that changes over the last decades have coalesced to create a relatively unique generation of young people. However, using large samples of U.S. high-school seniors from 1976 to 2006 (Total N=477,380), we found little evidence of meaningful change in egotism, self-enhancement, individualism, self-esteem, locus of control, hopelessness, happiness, life satisfaction, loneliness, antisocial behavior, time spent working or watching television, political activity, the importance of religion, and the importance of social status over the last 30 years. Today's youth are less fearful of social problems than previous generations and they are also more cynical and less trusting. In addition, today's youth have higher educational expectations than previous generations. However, an inspection of effect sizes provided little evidence for strong or widespread cohort-linked changes.
\end{abstract}

\section{Keywords}

Generation Me, Millennials, cohort effects, self-esteem, adolescents

Children today are tyrants. They contradict their parents, gobble their food, and tyrannize their teachers.

- Socrates (469 BC-399 BC)

What evidence did I have of a weak work ethic? Several books about the Millennial Generation, born between 1982 and 2002 [sic]. Most make the point that this cohort is self-absorbed to the point of narcissism and averse to concepts such as "working your way to the top." Many of these kids were raised to believe that they were "special." In the workplace, they are tough to manage. They dress like slobs, question authority, shrug off criticism.

-Nationally Syndicated Columnist Ruben Navarrette, June 28, 2008

It is seemingly axiomatic that every generation expresses concerns about the qualities of the next generation. In particular, social commentators have argued that socio-cultural changes over the last decades such as the rise of the culture of self-worth, a decline in social connectedness, and an increase in perceptions of threat have coalesced to create a relatively unique generation of young people (e.g., Bellah, Madsen, Sullivan, Swidler, \& Tipton, 1985; Lasch, 1979; Putnam, 2000; Twenge, 2000, 2006). Many of these accounts portray more recent generations in a fairly negative light. For example, Americans born in the 1970s, 1980s, and 1990s have been grouped into a single cohort and labeled "Generation Me" because they seem to have a heightened sense of egotism, self-esteem, and expectations for their future (Twenge, 2006). This generation is also alleged to exhibit elevated levels of misery and other symptoms of psychological distress (Twenge, 2006; but see Arnett, 2007). Likewise, 60 Minutes ran a story about members of the so-called "Millennial" generation (individuals born between 1982 and 2002) in the workplace and proclaimed that a "new breed of American worker is about to attack everything you hold sacred" (Textor, 2008). These Millennials were described as not trusting anyone over 30, not knowing how to work, and being too fragile to be critiqued because their " . . childhoods filled with trophies and adulation didn't prepare them for the cold realities of work" (Textor, 2008). Indeed, there seems to be a fairly widespread belief that members of the current generation of young people are considerably different from previous generations, in mostly negative ways.

The issues that should be relevant to scientific psychology are whether the evidence for generational differences is based on sound methodology and whether the differences are small or

\section{Corresponding Author:}

Kali Trzesniewski, Department of Psychology, University of Western Ontario, London, Ontario, Canada N6G 3K7.

E-mail: k.trz@uwo.ca 
large in magnitude. That is, how good are the data and how substantial are the differences between the current generation of youth and previous generations in terms of attitudes and personality characteristics? The goal of the present analyses is to evaluate evidence of cohort-related changes using a 30-year study of American high-school seniors. Specifically, we will test whether we can replicate the profile of Generation Me that has been described in previous studies (e.g., Twenge, 2006; Twenge \& Campbell, 2001; Twenge, Konrath, Foster, Campbell, \& Bushman, 2008). In particular, we will test this profile using 31 psychological constructs, such as misery (e.g., diminished happiness and life satisfaction, increased loneliness), confidence (e.g., higher self-esteem, measures of egotism and social comparison), and expectations (e.g., higher expectations for the future).

\section{Cohort Effects and Cross-Temporal Meta-Analytic Approaches}

A central psychological question is whether or not the social, historical, and cultural events of any given era exert a systematic influence on personality development (e.g., Elder, Modell, \& Parke, 1993; Nesselroade \& Baltes, 1974; Roberts \& Helson, 1997; Stewart \& Healy, 1989). Such effects are classified by developmental psychologists as cohort effects (e.g., Schaie, 1965), and clear evidence of cohort effects would have profound theoretical and practical implications. Theoretically, robust evidence of cohort effects challenges the idea that there is a "universal" age-related patterning to social and personality development (e.g., Baltes, Cornelius, \& Nesselroade, 1979) and indicates (albeit indirectly) that the sociocultural environment plays an important role in shaping psychological development (e.g., Bronfenbrenner \& Morris, 2006; Elder \& Shanahan, 2006; Twenge, 2000). ${ }^{1}$ Cohort effects may necessitate new expectations and ways of interacting with an entire generation of young people. Despite their potential importance, however, researchers have struggled with the task of isolating cohort effects from the effects of age and time of measurement for over 50 years (e.g., Baltes, 1968; Bell, 1953; Cattell, 1970; Costa \& McCrae, 1982; Donaldson \& Horn, 1992; Glenn, 1976; Kosloski, 1986; Nesselroade \& Baltes, 1974; Schaie, 1965).

Recently, Twenge and her colleagues (e.g., Twenge, 2000; Twenge \& Campbell, 2001; Twenge \& Im, 2007; Twenge, Zhang, \& Im, 2004) have developed a new method to examine cohort effects: the cross-temporal meta-analysis. This technique capitalizes on the extensive amount of questionnaire research conducted by psychologists over the last 50 or so years. The general strategy is to compute the association between the year of data collection and the average score on measures of personality or attitudes for samples with restricted variability in age (e.g., college student samples, high-school student samples). Twenge and her colleagues have found relatively large cohort differences for a wide variety of measures of attitudes and personal characteristics. For example, average levels of measures of trait anxiety in college student samples have increased more or less linearly from 1952 to 1993 (Twenge, 2000)-likewise levels of self-esteem have increased from 1965 to 1994 (Twenge \& Campbell, 2001). This suggests that college students born more recently are both more neurotic and have higher self-esteem than previous generations. These two trends are somewhat paradoxical given that self-esteem and measures of neuroticism are typically so negatively correlated that some authors have commented that both are indicators of the same latent construct (e.g., Judge, Erez, Bono, \& Thoresen, 2002). Moreover, cross-temporal meta-analyses indicated that internal locus of control scores have declined from 1960 to 2002, indicating that college students and children who participated in more recent studies reported that they are less in control of their own destinies than previous generations (Twenge et al. 2004).

\section{Methodological Concerns With Cross- Temporal Meta-Analytic Approaches}

The results of these meta-analytic studies are provocative; however, the cross-temporal meta-analytic technique for indentifying cohort-related changes in psychological characteristics is limited in terms of how the method is usually applied to the existing literature (Arnett, in press; Trzesniewski, Donnellan, \& Robins, 2008a). Foremost, the generalizability of these findings is simply uncertain because the samples typically included in the meta-analyses are not designed to make population inferences. The concern is that the constituent samples are often generated using nonprobability sampling techniques. For instance, it is common for researchers in social and personality psychology to use convenience samples in research, such as undergraduates in introductory courses who participate in research in exchange for course credit. These samples provide data quickly and in large numbers, but the individuals in the sample are not selected at random and they are not representative with respect to a defined population of interest. In these cases, it is not possible to estimate sampling errors or otherwise defend generalizations based on the sample (Pedhazur \& Schmelkin, 1991). Increased sample sizes cannot compensate for the limits on inference posed by nonprobability sampling techniques. This is perhaps one reason why Caspi (1998) remarked that sampling "continues to be psychology's Achilles' heel" (p. 370). In short, it is not clear how to precisely generalize findings from cross-temporal meta-analyses.

A second issue involves the level of analysis and the calculation of effect sizes from a cross-temporal meta-analysis. Cross-temporal meta-analyses initially yield ecological correlations (W.S. Robinson, 1950) or alerting correlations (Rosenthal, Rosnow, \& Rubin, 2000; see Helson, Kwan, John, \& Jones, 2002), which are calculated using summary statistics (e.g., sample means) rather than individual data points that contribute to those statistics. These kinds of results can be difficult to interpret in psychological terms because psychologists are accustomed to thinking about how well a predictor explains variability in a criterion variable assessed in a sample of individuals. For example, a psychologist may want to know how 

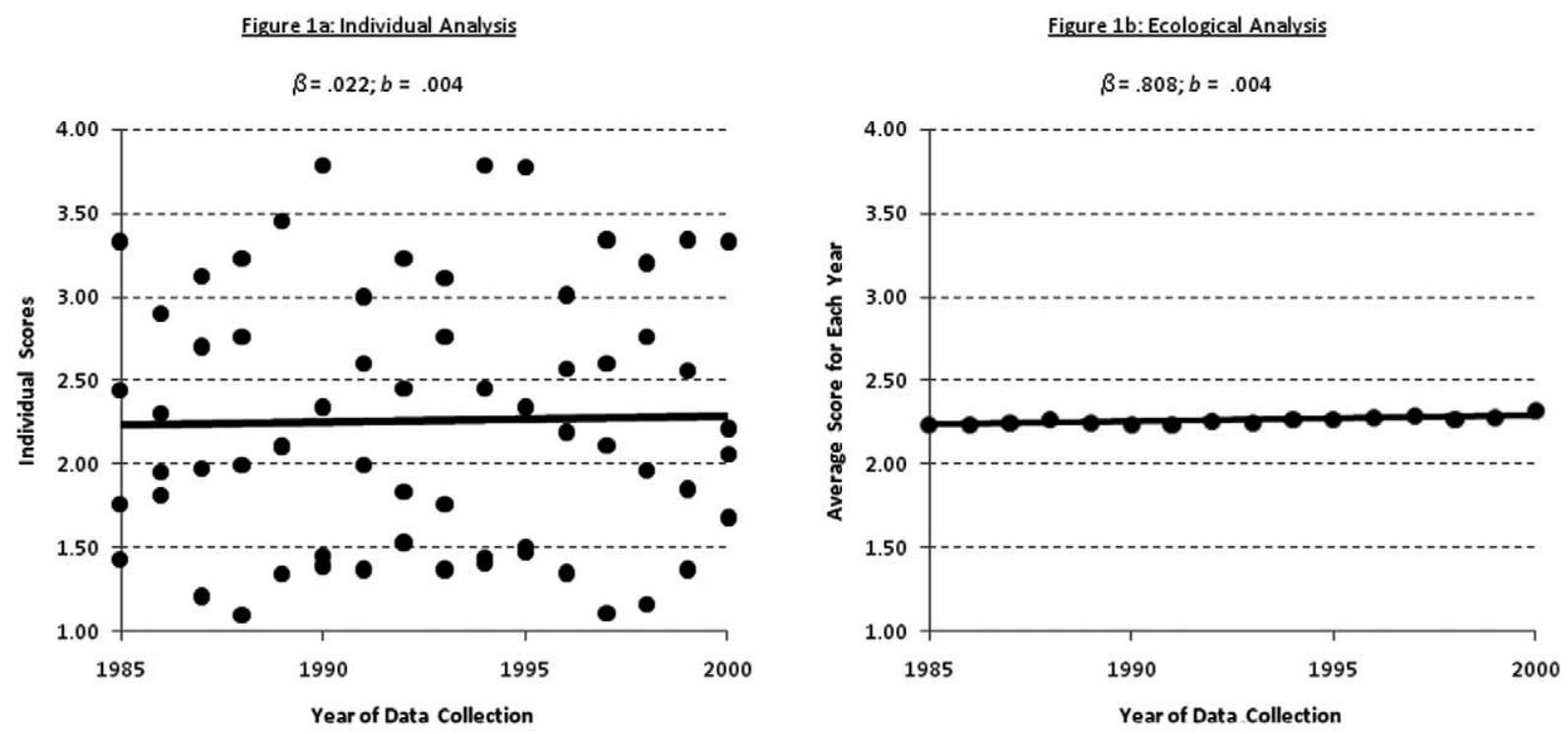

Fig. I. Graphical illustration of the difference between correlations at the individual level (a) and those from aggregated data using data in Table I (b).

strongly gender is associated with scores on self-esteem or how much variation in self-esteem is "explained" by gender. To answer this question, psychologists are used to interpreting statistics like coefficients of determination and regression effects at the level of individuals.

By contrast, rather than providing information about variability and prediction at the level of individuals, the initial results from a cross-temporal meta-analysis capture the associations between the year of data collection and the average yearly score for a given measure (e.g., see Table 1 in Twenge, 2000, p. 1011; Table 2 in Twenge \& Campbell, 2001, p. 334; Table 1 in Twenge et al., 2004, p. 313). Psychologists are often unaccustomed to thinking about accounting for variability in a construct at this level, and there is no guarantee that relations found at this level will be the same - or even similar torelations between individual scores and time of measurement. The important fact is that "correlations based on aggregated data (e.g., group means) can be dramatically larger or smaller (even in the opposite direction) than correlations based on individual scores" (Rosenthal et al., 2000, p. 2).

A concrete example may help illustrate this concern. Table 1 displays data from a hypothetical study in which the same psychological instrument was administered yearly from 1985 to 2000. At each year, a different set of 4 participants of the same age were randomly selected from the population to complete the measure at each year, so there are 64 participants in total. The overall mean across years was 2.26 . The correlation between year of data collection and individual scores on this measure was .02. However, a researcher who wanted to examine secular trends in this measure would focus on aggregated data and would therefore correlate the year of data collection with the average yearly score on this measure. To perform such an analysis, researchers would first obtain the mean of the
Table I. Hypothetical Likert-Type Scale Data

\begin{tabular}{lllllll}
\hline Year & Score I & Score 2 & Score 3 & Score 4 & $M$ & SD \\
\hline 1985 & 1.43 & 2.44 & 3.33 & 1.76 & 2.24 & 0.84 \\
1986 & 1.95 & 2.30 & 2.90 & 1.81 & 2.24 & 0.49 \\
1987 & 1.97 & 3.12 & 2.70 & 1.21 & 2.25 & 0.84 \\
1988 & 1.10 & 2.76 & 3.23 & 1.99 & 2.27 & 0.93 \\
1989 & 1.34 & 2.10 & 3.45 & 2.11 & 2.25 & 0.88 \\
1990 & 1.45 & 2.34 & 3.78 & 1.39 & 2.24 & 1.11 \\
1991 & 1.99 & 2.60 & 3.00 & 1.37 & 2.24 & 0.71 \\
1992 & 1.83 & 2.45 & 3.23 & 1.53 & 2.26 & 0.75 \\
1993 & 1.76 & 2.76 & 3.11 & 1.37 & 2.25 & 0.82 \\
1994 & 1.44 & 2.45 & 3.78 & 1.41 & 2.27 & 1.12 \\
1995 & 1.47 & 2.34 & 3.77 & 1.50 & 2.27 & 1.08 \\
1996 & 1.35 & 2.57 & 3.01 & 2.19 & 2.28 & 0.70 \\
1997 & 1.11 & 2.11 & 3.34 & 2.60 & 2.29 & 0.94 \\
1998 & 1.96 & 2.76 & 3.20 & 1.16 & 2.27 & 0.90 \\
1999 & 1.37 & 2.56 & 3.34 & 1.85 & 2.28 & 0.86 \\
2000 & 2.21 & 3.33 & 2.06 & 1.68 & 2.32 & 0.71 \\
\hline
\end{tabular}

measure at each year and then correlate that vector of 16 means with the year of data collection. In Table 1, this ecological correlation is . 81 - much larger than the individual correlation of .02. The reason for this discrepancy can be appreciated by comparing the two panels of Figure 1 with attention to the amount of variability in the dependent measures. The standard deviation of the individual-level scores $(0.76)$ is much higher than the standard deviation of the yearly averages $(0.02)$. These differences in the variance can create large differences between ecological and individual correlations. ${ }^{2}$

We want to be clear that Twenge and her colleagues take great care to avoid what is known as the ecological fallacy (W.S. Robinson, 1950) or the mistake of assuming that effects that apply at a macro level of analysis necessarily apply at a 
Table 2. Descriptive Statistics and Reliability of Study Constructs

\begin{tabular}{|c|c|c|c|c|c|c|c|}
\hline Construct & $N$ & Number of items & $\alpha$ & M & $S D$ & Minimum & Maximum \\
\hline Egotism & 468,973 & 2 & .71 & 4.92 & 1.07 & I & 7 \\
\hline Self-enhancement & 410,527 & I & - & 0.00 & 1.04 & -4.65 & 3.19 \\
\hline Individualism & 120,153 & 1 & - & 4.19 & 0.97 & 1 & 5 \\
\hline Self-esteem & 177,598 & 6 & .82 & 4.04 & 0.79 & I & 5 \\
\hline Locus of control & 82,088 & 7 & .66 & 2.26 & 0.66 & 1 & 5 \\
\hline Hopelessness & 89,942 & 8 & .68 & 2.64 & 0.63 & i & 5 \\
\hline Happiness & 440,720 & I & - & 2.05 & 0.58 & 1 & 3 \\
\hline Life satisfaction & 90,568 & 14 & .82 & 5.01 & 0.92 & 1 & 7 \\
\hline Loneliness & 77,303 & 6 & .70 & 2.31 & 0.76 & I & 5 \\
\hline Antisocial behavior & 108,106 & 14 & .83 & 3.50 & 5.77 & 0 & 56 \\
\hline Trust & 90,017 & 3 & .61 & 1.82 & 0.61 & 1 & 3 \\
\hline \multicolumn{8}{|l|}{ Cynical } \\
\hline School & 122,070 & 2 & .52 & 2.74 & 0.91 & 1 & 5 \\
\hline Government & 87,009 & 5 & .72 & 3.10 & 0.58 & 1 & 5 \\
\hline \multicolumn{8}{|l|}{ Expectations } \\
\hline Graduate college & 451,344 & 1 & - & 3.02 & 1.12 & 1 & 4 \\
\hline Go to graduate school & 443,516 & I & - & 2.38 & 1.02 & 1 & 4 \\
\hline \multicolumn{8}{|l|}{ Materialism } \\
\hline Care about trends & 86,829 & 2 & 0.40 & 2.42 & 0.73 & 1 & 4 \\
\hline Important have money & 89,758 & I & - & 2.79 & 0.89 & 1 & 4 \\
\hline Tolerance of advertising & 87,116 & 1 & - & 2.60 & 1.40 & 1 & 5 \\
\hline \multicolumn{8}{|l|}{ Hard working } \\
\hline Do not want to work hard & 84,172 & 1 & - & 1.72 & 0.90 & I & 3 \\
\hline Cut school & 445,669 & I & - & 1.69 & 1.30 & 1 & 7 \\
\hline Watch TV & 88,653 & 1 & - & 4.14 & 1.66 & 1 & 7 \\
\hline Homework & 74,265 & I & - & 2.85 & 1.41 & 1 & 7 \\
\hline Work & 445,297 & I & - & 4.03 & 2.34 & I & 8 \\
\hline \multicolumn{8}{|l|}{ Social concern } \\
\hline Contributed to charity & 86,148 & 9 & - & 0.67 & 1.08 & 0 & 9 \\
\hline Political activism & 86,958 & 6 & - & 0.38 & 0.78 & 0 & 6 \\
\hline Think about the government & 279,957 & I & - & 3.07 & 0.98 & I & 5 \\
\hline Think about social issues & 312,556 & I & - & 3.13 & 0.86 & I & 5 \\
\hline Fear of social problems & 87,318 & II & .79 & 2.52 & 0.54 & I & 4 \\
\hline Importance of religion & 442,620 & I & - & 2.75 & 1.02 & 1 & 4 \\
\hline \multicolumn{8}{|l|}{ Importance of status at school } \\
\hline Earned status & 72,551 & 3 & .80 & 3.17 & 0.99 & I & 5 \\
\hline Unearned status & 72,664 & 2 & .31 & 2.90 & 1.08 & 1 & 5 \\
\hline
\end{tabular}

more micro level of analysis. In particular, they use the unstandardized regression coefficient from their cross-temporal metaanalyses to translate their results into a $d$-metric effect size that can be presumably interpreted at the level of the individual (e.g., see Twenge et al., 2004). Specifically, they use the regression equation to compute a predicted average score for a population at the first and last time points covered in their analysis. They then compute the difference between those two predicted scores and divide that value by the average standard deviation of the measure in question based on the available estimates of variability. For example, Twenge et al. (2008) examined cohort changes in narcissism for college students and found that average scores on the Narcissistic Personality Inventory (Raskin \& Terry, 1988) increased .09 scale points per year from 1982 to 2006 . They used this equation to predict the average score in 1982 (15.06) and the average score in 2006 (17.29) and then divided that difference (2.23) by the average standard deviation for the samples included in the metaanalysis (6.86). This resulted in a $d$-metric increase of .33 or about one third of a standard deviation increase in the mean from 1982 to 2006.

There are, however, a few potential issues with this approach of translating cross-temporal meta-analytic findings into individual level effects using this $d$-metric approach. Foremost, W.S. Robinson (1950) provided an example of the dramatic case where the sign of the ecological correlation (e.g., average yearly score on a measure correlated with year of data collection) and the sign of the individual coefficients (e.g., individual scores correlated with year of data collection) were different: one was positive and one was negative (see also Cooper $\&$ Patall, 2009). If such a phenomenon were operating, then the $d$-metric approach used by Twenge and her colleagues would be wrong in terms of the direction of the difference. The major issue here is that researchers typically do not have access to all the individual-level and aggregated data when conducting a cross-temporal meta-analysis, so there is often no way to verify whether the signs of the individual and ecological correlations are in the same direction. 
Trzesniewski and Donnellan

A second and less drastic concern has to do with the possibility of bias in the effect size estimation with the $d$-metric approach. Twenge et al. (2004) have noted that "this technique probably still results in somewhat higher effect sizes" (pp. 313-314). The concern again is that individual level and aggregated data are often not simultaneously available when conducting cross-temporal meta-analyses, so it is difficult to estimate the degree of bias in the effect size estimation based on the aggregated data. We attempt to examine this issue in our research by taking advantage of an extremely large data set in which the same measures were given to different sets of individuals every year from 1976 to 2006. Thus, we can compare individual effects (i.e. by correlating year of data collection with individual scores) and ecological effects (i.e., by correlating the year of data collection with the average score for a given year) to examine differences between the two kinds of statistics.

A final related issue regarding variability has much broader implications. That is, the focus on average levels of constructs for birth cohorts may overshadow the considerable amount of individual variability present within a given generation. It is a psychological truism that variability is ubiquitous, and this is especially true of the amount of variation within large and heterogeneous social categories like birth cohort member. Hyde (2005) recently discussed issues regarding the interpretation of gender differences, and her discussion is relevant for considering birth cohort differences. Hyde expressed the concern that much of the literature concerning gender differences has been interpreted as evidence that males and females are "vastly" different despite the fact that there is a considerable amount of within-gender variation and the fact that many of the effect sizes for gender differences for major psychological variables were small to nonexistent. Moreover, given the existing data, she noted that there are potential dangers of making inflated claims of gender differences in such areas as the workplace, parenting, and intimate relationships.

The sorts of concerns that Hyde (2005) raises about the costs of inflated claims regarding gender differences may also apply to cohort differences. For example, Twenge (2006) dedicates an entire chapter of her popular book to providing advice to parents and policy makers for dealing with members of socalled Generation Me. The issue is that the size of generational effects may not warrant these kinds of recommendations. Furthermore, evidence supporting the underlying mechanisms linking parenting practices and social policies to changes in psychological constructs is generally lacking. For example, Twenge (2006) places a considerable amount of blame on the self-esteem movement for the generational changes in the direction of Generation Me and suggests that such programs should be abandoned. She notes that "instead of creating well-adjusted, happy children, the self-esteem movement has created an army of little narcissists" (p. 223). However, we have pointed out that there is very little direct evidence to support this particular claim (Trzesniewski, Donnellan, \& Robins, 2008a), whereas there is meta-analytic evidence that selfesteem programs can be effective (O'Mara, Marsh, Craven,
\& Debus, 2006). Thus, the messages being conveyed to the general public may not reflect the complexities of the scientific literature.

\section{The Present Investigation}

In sum, we believe that the existing evidence for cohort-related differences along the lines of the so-called Generation Me profile is limited because of sampling concerns. Specifically, we are referring to the conclusion that individuals born in the 1970s or later have higher scores than members of earlier birth cohorts on measures of self-esteem, external locus of control, and indices of selfishness and also have lower scores on measures of social concern and indices of well-being and happiness (i.e., misery, according to Twenge, 2006). We also believe that there are lingering questions about the exact size and scope of generational differences and how these differences should be interpreted by the scientific community. Accordingly, the goal of the present research is to examine the evidence for the Generation Me hypothesis using the Monitoring the Future project (MTF; Johnston, Bachman, \& O’Malley, 2003).

The MTF project is a series of nationally representative samples of high-school seniors that have been collected from the mid-1970s to the mid-2000s (detailed information about the sample can be found at http://www.monitoringthefuture.org/). The time span of the MTF project will allow us to contrast Generation Me (i.e., those born in the 1970s or later) with the earlier generation of Americans and evaluate how well previously identified cross-temporal meta-analysis findings generalize to a representative sample of young Americans. Previous research has examined secular changes using the MTF data (e.g., Reynolds, Stewart, MacDonald, \& Sischo, 2006, examined expectations; Trzesniewski et al., 2008b, examined egotism in the form of academic self-enhancement), but, to our knowledge, this is the first study to examine secular changes across a large number of psychological constructs to directly evaluate the broad scope of claims made about Generation Me and to use all waves of the electronically available MTF data up to 2006.

\section{Method}

Participants and Procedure. The data for this study come from the MTF project, an ongoing study of young Americans beginning in 1976 (see Bachman, Johnston, \& O’Malley, 1996; Johnston, O'Malley, Schulenberg, \& Bachman, 1998, for a more detailed description). Briefly, students are randomly assigned to complete one of six questionnaires, each with a different subset of topical questions but all containing a set of "core" questions (see Table 2 for sample sizes for each construct). Across the 30 years of the study, 477,380 (51.4\% female; $84.1 \%$ Caucasian) high-school seniors have participated.

A three-stage sampling procedure was employed. Stage 1 involved the selection of particular geographic areas, Stage 2 involved the selection of one or more schools in each area, and Stage 3 involved the selection of students within each school. 
The last stage was usually accomplished by selecting intact classes. This procedure results in an area probability sample of the 48 coterminous states. Data were collected following standardized procedures via closed-ended questionnaires administered in classrooms by University of Michigan representatives and their assistants.

The response rate for schools across the 30 years was between $95 \%$ and $99 \%$. The average response rate for students was $80 \%$ in the 1970 s, $83 \%$ in the 1980 s, $84 \%$ in the 1990 s, and $83 \%$ in the 2000s. It is reported that the most common reason for nonparticipation is being absent from school that day, followed by scheduling interferences, such as school field trips. Only about $1 \%$ of students present in school during testing refused to participate.

Measures. Table 2 provides descriptive information for the constructs used in the present study including internal consistency (alpha) reliabilities for scales containing more than one item.

Measures of Egotism, Individualistic Attitudes, and Self-Esteem. We used two items to assess egotism: "Compared with others your age around the country, how do you rate yourself on school ability?" and "How intelligent do you think you are compared with others your age?". Participants rated the items from 1 (far below average) to 7 (far above average). The scale is keyed so that high scores reflect more egotism.

We used an unstandardized residual score (computed via regression using data from all years) reflecting the discrepancy between egotism (self-perceived intelligence) and self-reports of high-school grades to assess self-enhancement. Specifically, we regressed self-perceived intelligence on self-reports of grades using all available data and saved the unstandardized residuals. There is evidence that self-reported grades are reasonable indicators of actual grades. For example, Kuncel, Credé, and Thomas (2005) reported that the correlation between self-reported grades and actual GPA was .82 for high-school students based on a meta-analysis involving 44,176 students. They also note that "self-reported grades generally predict outcomes to a similar extent as actual grades" ( $p$. 76). Standardized test scores were not available in the publically available MTF data, but the correlation between selfenhancement based on grades and self-enhancement based on self-reported SAT scores in college students was around .90 (e.g., Trzesniewski et al., 2008b); thus, it is unlikely that the secular trends would have been different if test scores had been used as a criterion instead of self-reported grades. The scale is keyed so that high scores reflect more self-enhancement.

We assessed individualism by asking participants to respond to the statement "People should do their own thing, even if other people think it's strange" on a scale of 1 (disagree) to 5 (agree). The scale is keyed so that high scores reflect more individualism.

We assessed self-esteem with a six-item abbreviated version of the Rosenberg (1965) Self-Esteem scale. Participants used a 1 (disagree) to 5 (agree) scale to respond to the following items: "I take a positive attitude towards myself," "I feel that I am a person of worth, at least on an equal basis with others," "I am able to do things as well as most other people," "On the whole, I am satisfied with myself," "I feel I do not have much to be proud of (reverse scored)," and "At times I think I am no good at all (reverse scored)." The scale is keyed so that high scores reflect higher self-esteem. The two reverse-scored items were not included until 1977. We used the four-item scale for 1976 and the six-item scale for the remaining years.

\section{Measures of Helplessness, Misery, Antisocial Behavior,} and Life Satisfaction. We used a seven-item scale to assess locus of control. Participants used a 1 (disagree) to 5 (agree) scale to respond to the following items: "Good luck is more important than hard work for success," "Every time I try to get ahead, something or somebody stops me," "Planning only makes a person unhappy since plans hardly every work out anyway," "People who accept their condition in life are happier than those who try to change things," "People like me don't have much of a chance to be successful in life," "When I make plans, I am almost certain I can make them work (reverse scored)," and "Planning ahead makes things turn out better (reverse scored)." An eighth item was available ("I believe a person is master of his/her own fate (reverse scored)," but this item reduced the alpha reliability of the scale from .66 to .56 and was therefore not included in the scale. The scale was keyed so that high scores reflect an external locus of control, and lower scores reflect an internal locus of control.

We used an eight-item scale to assess hopelessness. The first three items were rated from 1 (get much better) to 5 (get much worse). The other five items were rated from 1 (disagree) to 5 (agree). The items were as follows: "Looking ahead to the next five years, do you think that things in this country will get better or worse?", "Looking ahead to the next five years, do you think that things in the rest of the world will get better or worse?", "How do you think your own life will go in the next five years-do you think it will get better or worse?", "The human race has come through tough times before, and will do so again (reverse scored)," "When I think about all the terrible things that have been happening, it is hard for me to hold out much hope for the world," "I often wonder if there is any real purpose to my life in light of the world situation," "My guess is that this country will be caught up in a major world upheaval in the next 10 years," and "It does little good to clean up air and water pollution because this society will not last long enough for it to matter." The scale is keyed so that high scores reflect more hopelessness.

We used a single item to assess happiness. Participants were asked "Taking all things together, how would you say things are these days - would you say you're very happy, pretty happy, or not too happy these days?" This item was rated from 1 (very happy) to 3 (not too happy). The scale is keyed so that high scores reflect more unhappiness.

We used a 14-item scale to assess life satisfaction. Participants were asked to rate their satisfaction with the following items: "Your job," "The neighborhood where you live," 
"Your personal safety in your neighborhood, on your job, and in your school— safety from being attacked and injured in some way," "Your educational experience," "Your friends and other people you spend time with," "The way you get along with your parents," "Yourself," "Your standard of living - the things you have like housing, car, furniture, recreation, and the like," "The amount of time you have for doing things you want to do," "The way you spend your leisure time-recreation, relaxation, and so on," "Your life as a whole these days," "The way our national government is operating," "The amount of fun you are having," and "The safety of things you own from being stolen or destroyed in your neighborhood, on your job, and in your school." Participants indicated their satisfaction for each domain from 1 (completely dissatisfied) to 7 (completely satisfied). The scale is keyed so that high scores reflect more positive life satisfaction.

We used a six-item scale to assess loneliness. Participants used a 1 (disagree) to 5 (agree) scale to respond to the following items: "A lot of times I feel lonely," "There is always someone I can turn to if I need help (reverse scored)," "I often feel left out of things," "There is usually someone I can talk to if I need to (reverse scored)," "I often wish I had more good friends," and "I usually have a few good friends around that I can get together with (reverse scored)." The scale is keyed so that high scores reflect more loneliness. These items were not asked in 1976.

We used a 14-item scale to assess antisocial behavior. Participants were asked to use a scale of 1 (not at all) to 5 ( 5 or more times) to indicate how often they participated in the following antisocial behaviors during the past 12 months: "Hit an instructor or supervisor," "Taken part in a fight where a group of your friends were against another group," "Gotten into a serious fight in school or work," "Hurt someone badly enough to need bandages or a doctor," "Used a knife or gun or some other thing (like a club) to get something from a person," "Taken something not belonging to you worth under $\$ 50$," "Taken something not belonging to you worth over $\$ 50$," "Taken something from a store without paying for it," "Taken a car that didn't belong to someone in your family without permission of the owner," "Taken part of a car without permission of the owner," "Gone into some house or building when you weren't supposed to be there," "Damaged school property on purpose," "Damaged property at work on purpose," and "Set fire to someone's property on purpose." Items were recoded to range from 0 to 4 and then were summed. This procedure was selected so that 0 represented an absence of a particular antisocial activity. The scale is keyed so that high scores reflect more antisocial behavior.

Measures of Interpersonal Trust and Cynicism. We used a three-item scale to assess trust. Participants were asked "Generally speaking, would you say that most people can be trusted or that you can't be too careful in dealing with people?", "Would you say that most of the time people try to be helpful or that they are mostly just looking out for themselves?", and "Do you think most people would try to take advantage of you if they got a chance or would they try to be fair?" Items were rated on a 3-point scale. The scale is keyed so that high scores reflect more trust.

We used two scales to assess cynicism: cynicism for school and cynicism for government. Cynicism for school was assessed with two items: "How often do you feel that the school work you are assigned is meaningful and important?", which participants rated from 1 (never) to 5 (almost always; reverse scored), and "How important do you think the things you are learning in school are going to be for your later life?", which participants rated from 1 (not at all important) to 5 (very important; reverse scored). Cynicism for government was assessed with five items: "Do you think some of the people running the government are crooked or dishonest?", which participants rated from 1 (most of them are crooked or dishonest) to 5 (none at all are crooked or dishonest; reverse scored); "Do you think the government wastes much of the money we pay in taxes?", which participants rated from 1 nearly all of the tax money is wasted) to 5 (no tax money is wasted; reverse scored); "How much of the time do you think you can trust the government in Washington to do what is right?", which participants rated from 1 (almost always) to 5 (never); "Do you feel that the people running the government are smart people who usually know what they are doing?", which participants rated from 1 (they almost always know what they are doing) to 5 (they never know what they are doing); and "Would you say the government is pretty much run for a few big interests looking out for themselves, or is it run for the benefit of all the people?", which participants rated from (nearly always run for a few big interests) to 5 (nearly always run for the benefit of all people; reverse scored). Both scales were keyed so that high scores reflect higher cynicism.

\section{Measures of Academic Expectations, Materialism, and} Attitudes About Work. We assessed expectations with items that asked students how likely it was that they will graduate from a 4-year college and attend graduate or professional school after college. They rated these items from 1 (definitely won't) to 4 (definitely will). Although these two items were highly correlated $(r=.61)$, we analyzed them separately given the importance of these variables to debates about the educational plans of today's youth. The scale is keyed so that high scores reflect higher expectations for the future.

We assessed materialism in three ways. First, participants were asked two questions: "How much do you care about having the latest fashion in your clothes, records, leisure activities, and so on?" and "How much do you care about whether your family has most of the things your friends and neighbors have?" These items were rated from 1 (not at all) to 4 (very much). Second, we asked participants to rate the importance of "having lots of money" in their lives on a scale of 1 (not important) to 4 (extremely important). Finally, we asked participants to respond to the following statement on a scale from 1 (disagree) to 5 (agree): "There is nothing wrong with advertising that gets people to buy things they don't really need." 
These scales are keyed so that high scores reflect more materialism.

We assessed hard working attitudes in five ways. First, we used an item that asked participants "To what extent do you think not wanting to work hard will prevent you from getting the kind of work you would like to have?" using a 1 (not at all) to 3 (a lot) scale. The scale is keyed so that high scores reflect a greater worry about being able to work hard. Second, we used an item that asked participants to reply to the question "During the last four weeks, how many whole days of school have you missed because you skipped or 'cut'?" using a 1 (none) to 7 (11 or more) scale. The scale is keyed so that high scores reflect less commitment to school. Third, we used an item that asked participants to reply to the question "How much TV do you estimate you watch on an average weekday?" using a 1 (none) to 5 ( 5 hours or more) scale. The scale is keyed so that high scores reflect more time spent watching TV. Fourth, we used an item that asked participants to reply to the question "How many hours do you spend in an average week on all your homework including both in school and out of school." using a 1 (0 hours) to 7 (25 or more hours) scale. Fifth, we used an item that asked participants to reply to the question "On average over the school year, how many hours per week do you work in a paid or unpaid job?" using a 1 (none) to 8 (more than 30 hours) scale. The last two scales are keyed so that high scores reflect more hard work.

Measures of Social Awareness and Activity. We assessed social concern in four ways. First, participants reported their charitable contributions by indicating whether they have ever given money to any of the following organizations: "The United Fund or other community charities," "International relief organization (CARE, UNICEF, etc.)," "Minority group organizations (NAACP, SCLC, etc.)," "Church or religious organizations," "Political parties or organizations," "Citizen lobbies (Common Cause, Public Citizen, etc.)," "Charities to help fight diseases (Cancer, Heart Disease, etc.)," "Organizations concerned with population problems (Planned Parenthood, ZPG, etc.)," and "Organizations concerned with environmental problems (Sierra Club, Friends of Earth, etc.)." Participants were given one point for each organization they had contributed to, and total scores were computed by summing across the organizations. Second, participants reported whether they had ever taken part in any of the following political activities: "Vote in a public election," "Write to public officials," "Give money to a political candidate or cause," "Work in a political campaign," "Participate in a lawful demonstration," and "Boycott certain products or stores." Participants were given one point for each activity they had completed, and total scores were computed by summing across the activities. Third, participants indicated their interest in government by responding to the question "Some people think about what's going on in government very often, and others are not that interested. How much of an interest do you take in government and current events?" using a 1 (no interest at all) to 5 (a very great interest) scale. Fourth, participants indicated their interest in social issues by responding to the question "Some people think a lot about the social problems of the nation and the world, and about how they might be solved. Others spend little time thinking about these issues. How much do you think about such things?" using a 1 (never) to 5 (a great deal) scale. All scales are keyed so that high scores reflect more social concern.

Measures of the Sociocultural Climate and the Importance of Religion. We used an 11-item scale to assess fear of social problems. Participants were asked how often they worry about each of the following issues: "Chance of nuclear war," "Population growth," "Crime and violence," "Pollution," "Energy shortages," "Race relations," "Hunger and poverty," "Using open land for housing or industry," "Urban decay," "Economic problems," and "Drug abuse." Participants rated each item from 1 (never) to 4 (often). The scale is keyed so that high scores reflect greater fear of social problems.

We assessed importance of religion by asking participants to respond to the question "How important is religion in your life?" using a 1 (not important) to 4 (very important) scale. The scale is keyed so that high scores reflect a higher importance of religion. We assessed status by using an item that asked students to respond to the question "How important is each of the following for being looked up to or having high status in your school?" using a 1 (no importance) to 5 (very great importance) scale. We created an earned status scale with the items "Getting good grades," "Knowing a lot about intellectual matters," and "Planning to go to college." We created an unearned status scale with two items: "Having a nice car" and "Coming from the right family." The last two scales are keyed so that high scores reflect higher status.

\section{Predictors}

Cohort. Cohort was coded as year of data collection.

Demographics. Ethnicity was coded as Caucasian or nonCaucasian (for privacy issues, further breakdown of ethnic group was not available); gender was also reported. However, we found little evidence that gender or ethnic group moderated any of the analyses given that neither interaction term accounted for more than $1 \%$ of the variance in any of the analyses.

\section{Results}

Overview of Analyses and Notes on Effect Size Interpretation. The results of primary analyses are displayed in Table 3. In addition to examining the zero-order correlation between each construct and birth cohort (i.e., year of data collection; column 2 in Table 3), we examined mean level differences between birth cohorts by calculating a $d$-metric effect size (see column 10 in Table 3) comparing the average score on each measure from individuals assessed between 2001 and 2006 (i.e., column 8 in Table 3) with the average score on each measure from individuals assessed between 1976 and 1980 (i.e., column 3 in Table 3). This comparison provides another 


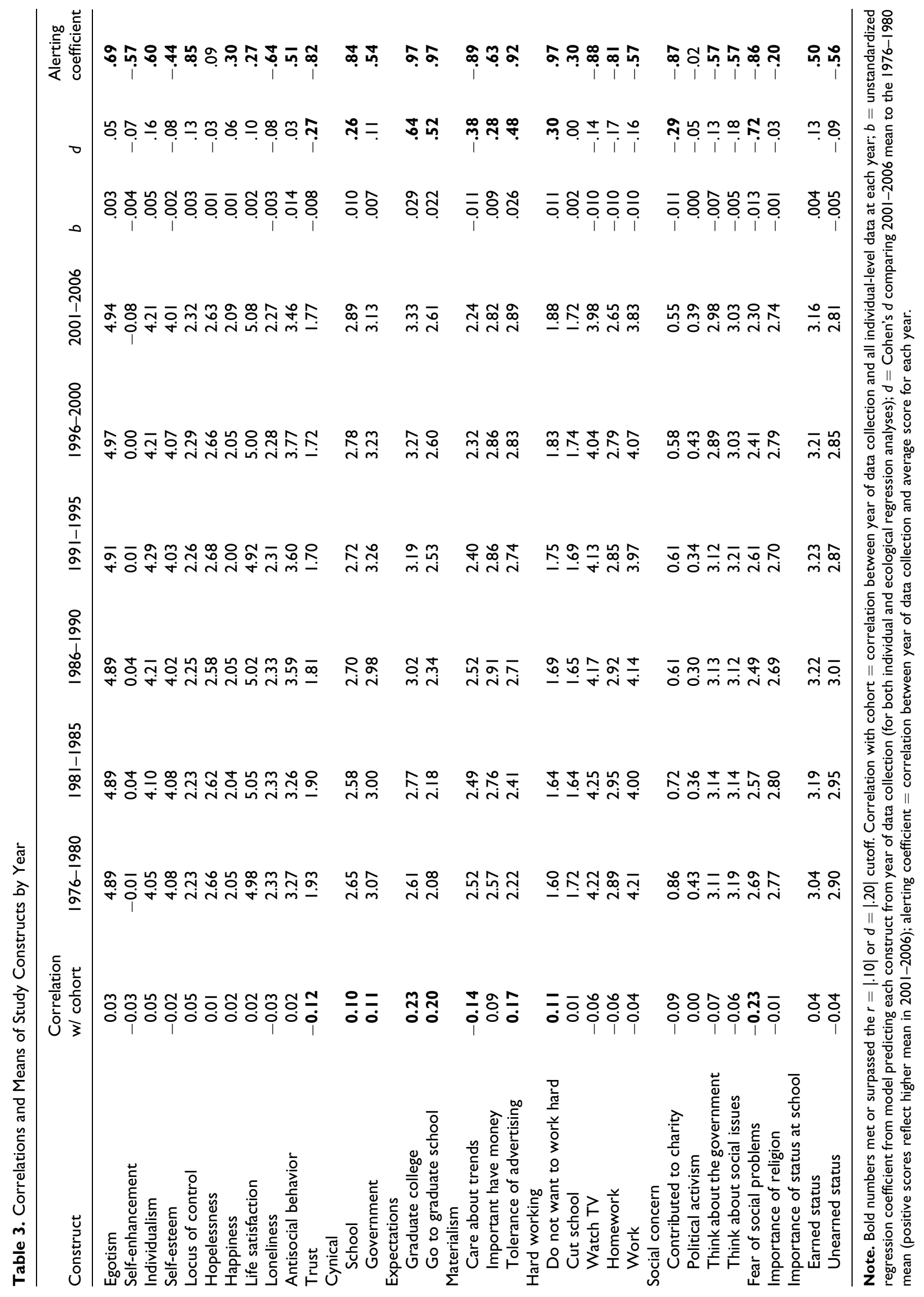


test of the cohort hypothesis because it directly compares the most recent members of Generation Me (i.e., individuals assessed in 2001-2006 who were born after 1980) with a previous generation (i.e., individuals assessed in 1976-1980 who were all born before 1965). A positive $d$ indicates that Generation Me scored higher on a given measure than did the previous generation. Except where stated otherwise, there was no compelling evidence for curvilinear trends for cohort.

Given the large sample sizes, we focused on effect sizes rather than significance levels. Statistical significance testing is not terribly useful because even the smallest of effects would reach the threshold of significance given the sample sizes in question. This raises an important issue over the appropriate standards for interpreting effect sizes. This is a subjective undertaking and we refer to Kline's (2004) comment that "this is not unscientific because the evaluation of all findings in science involves some degree of subjectivity" (p. 135). We elected to discuss all effects that met or surpassed Cohen's (1988) guideline of a small effect (i.e., an $r$ of $|.10|$ or a $d$ of $|.20|$ ). Our decision is consistent with Hyde's (2005) use of Cohen's guidelines for interpreting the size of gender differences, another controversial research area with implications that are relevant to the popular understanding of psychological research findings (see Hyde, 2005, pp. 586-587). Our cutoff is also consistent with another benchmark: the typical effect sizes in social psychology. Richard, Bond, and Stokes-Zoota (2003) compiled meta-analytic findings from 100 years of research and noted that a correlation of .10 was "small" relative to most effects, whereas effects of .30 or more were relatively "large" (see also Hemphill, 2003). Thus, a cutoff of $|.10|$ for a small effect seemed reasonable in light of these normative considerations.

To be sure, we recognize that small correlations can correspond to truly important effects. For example, Rosenthal (1990) reported that the point biserial correlation between a daily dose of a small amount of aspirin (vs. a placebo) and a reduced risk of heart attacks was .034 in a study of 22,000 physicians. This is an impressive result because the independent variable involved a fairly minimal manipulation and the dependent variable literally involved issues of life and death. Likewise, Roberts, Kuncel, Shiner, Caspi, and Goldberg (2007) reviewed evidence for the associations between personality traits and life outcomes like mortality, divorce, and attainment in educational and occupational settings. They found generally "small" effects using conventional benchmarks; however, the more important consideration was the fact that their dependent variables had clear applied value with relatively unambiguous interpretations (e.g., death and income). By comparison, the real world relevance of many of the outcomes that we examine (e.g., the average self-esteem score) is not so clear-cut because the dependent variables are measured on scales with arbitrary metrics (see Blanton \& Jaccard, 2006). In such an instance, it can be much more difficult to interpret the practical meaning of an effect size.

Indeed, the interpretation of the importance of an effect size involves considerations of the nature of the independent and dependent variables (see Prentice \& Miller, 1992). We could use a $|.03|$ figure as a benchmark for interpreting generational changes as meaningful. However, this strikes us as inappropriate in light of the variables in question (i.e., birth cohort and self-report measures of attitudes and personality characterizations), and indeed, equating small generational effects to the size of the aspirin/heart-attack association is potentially misleading given differences in the nature of the independent and dependent variables. It is also important to evaluate the level of consistency between the observed effect sizes and expectations based on previous work. Consider that Twenge (2008) recently argued that the sociocultural environment has "strong" effects on personality traits (e.g., see p. 1446). This generates expectations for observed effect sizes that are considerably larger than .03 .

We recognize that other researchers might prefer either more liberal or conservative standards; we stipulate that this is a judgment call. It is possible that a very small generational change (e.g., $r$ s of .06 over 30 years) for a particular personality trait or attitude may have a large impact on society; however, we believe that the burden of proof rests on those who want to claim that correlations of such size are practically important by linking such effects to "tangible costs and benefits that can be observed" (Blanton \& Jaccard, 2006, p. 37) and readily understood. To our minds, there are circumstances in which effects of .03 or .06 are likely to be too small to have practical consequences.

\section{Do Today's Youth Have Higher Self-Esteem and More Egotistic and Individualistic Attitudes Than Previous Generations?}

Egotism. Cohort was unrelated to egotism $(r=.03)$. Highschool students in the 1970 s and 2000 s were roughly equally likely to think they were smarter than others $(d=.05)$.

Self-enhancement. Cohort was unrelated to self-enhancement $(r=-.03, d=-.07)$.

Individualism. Cohort was uncorrelated with individualism $(r=.05, d=.16)$.

Self-esteem. Cohort was uncorrelated with self-esteem $(r=-.02, d=-.08) .{ }^{3}$ Based on these results, we concluded that the evidence for dramatic changes in self-esteem, egotism, and individualism was not compelling.

\section{Are Today's Youth More Helpless, Miserable, Lonely, and Antisocial Than Previous Generations?}

Locus of control. Cohort was uncorrelated with locus of control $(r=.05, d=.13)$.

Hopelessness. Cohort was uncorrelated with hopelessness $(r=.01, d=-.03)$.

Happiness. Cohort was uncorrelated with happiness $(r=.02$, $d=.06$ ).

Life satisfaction. Cohort was unrelated to life satisfaction $(r=.02, d=.10)$.

Loneliness. Cohort was unrelated with loneliness $(r=-.03$, $d=-.08)$. 
Antisocial behavior. Cohort was unrelated with antisocial behavior ( $r=.02, d=.03$ ). Based on these results, we concluded that the evidence of increased misery was not compelling.

\section{Are Today's Youth More Cynical and Less Trusting?}

Trust. Cohort was negatively related to trusting others $(r=$ $-.12)$. High-school seniors were more trusting in the $1970 \mathrm{~s}$ than in the 2000s $(d=-.27)$. This finding is consistent with trends reported by R.V. Robinson and Jackson (2001) who also found indications of cohort-linked declines in trust.

Cynicism. Cohort was positively correlated with being cynical about the usefulness of school $(r=.10)$. High-school seniors in the 1970 s were more likely to believe school was useful than students in the 2000s $(d=.26)$. Cohort was positively related to cynicism towards the government $(r=$ $.11, d=.11)$. Thus, there are indications that more recent cohorts are less trusting and more cynical about the usefulness of school and the trustworthiness of governmental institutions.

\section{Do Today's Youth Want and Expect More Than Previous Generations?}

Expectations. Cohort was positively related to expecting to graduate from college $(r=.23)$ and expecting to go to graduate or professional school $(r=.20)$. High-school students in the 1970 s had lower expectations for graduating from college $(d=.64)$ and going to graduate school $(d=.52)$ than students in the 2000 s. In the 1970 s, only $32.2 \%$ of students in the MTF data sets said they will definitely graduate from college, whereas $59.8 \%$ of the participants in 2000 s said they will definitely graduate from college. Similarly, in the $1970 \mathrm{~s}, 9.7 \%$ said they will go to graduate school, whereas in the $2000 \mathrm{~s}, 22.5 \%$ said they will definitely go to graduate school. Thus, we found evidence for cohort-linked changes in expectations for the future, at least in terms of educational attainment.

Materialism. Cohort was negatively related to caring about the latest trends ( $r=-.14, d=-.38$ ). Cohort was positively correlated with a feeling that having a lot of money is important in life $(r=.09)$, although there was a curvilinear trend for this item ( $\beta$ for quadratic term $=-.10)$. The importance of having a lot of money increased linearly from the 1970s through 1990 $(M \mathrm{~s}=2.57$ vs. $2.91 ; d=.38)$, then leveled off and even decreased very slightly from 1990 to the 2000s $(M \mathrm{~s}=2.91$ vs. $2.82 ; d=-.10)$. Finally, cohort was positively correlated with believing it is okay to have advertising that gets people to buy things they don't need ( $r=.17, d=.48)$. Thus, there were mixed cohort-linked changes in terms of materialism.

Are Today's Youth Lazier Than Previous Generations? Cohort was positively related to believing that not wanting to work hard will prevent one from getting a desired job (i.e., "To what extent do you think not wanting to work hard will prevent you from getting the kind of work you would like to have?"; $r=.11, d=.30)$. Cohort was uncorrelated with number of days of cutting school per month $(r=.01)$, number of hours spent watching TV per week $(r=-.06)$, number of hours spent on homework per week $(r=-.06)$, and number of hours worked per week during the school year $(r=-.04)$. Thus, there was little indication that more recent cohorts were less invested in working hard than previous cohorts.

\section{Are Today's Youth Less Socially Active and Aware Than} Previous Generations? Cohort was negatively correlated with financial contributions to charities $(r=-.09)$. In the $1970 \mathrm{~s}$, $46.0 \%$ of high-school seniors had contributed to one or more charities, whereas in the 2000 s only $33.2 \%$ had contributed to at least one charity. However, cohort was uncorrelated with civic engagement $(r=.00)$. In the 1970 s, $28.3 \%$ of high-school seniors had participated in at least one form of activism and $25.4 \%$ had participated in the 2000s. Cohort was not related to interest in government and current events $(r=-.07)$. There was no change in the amount high-school seniors thought about social issues $(r=-.06)$. Thus, we found little indication of dramatic increases in apathy in more recent cohorts.

\section{Cohort Differences in Perceptions of the Sociocultural Climate and the Importance of Religion}

Fear of social problems. Cohort was negatively related to amount of worry about threats from social problems such as war, pollution, crime, and poverty $(r=-.23, d=-.72)$.

Importance of religion. Cohort was unrelated to importance of religion $(r=-.01, d=-.03)$.

Status. Cohort was unrelated to basing school status on accomplishments $(r=.04, d=.13)$. Cohort was unrelated to basing school status on materialism $(r=-.04, d=-.09)$. In short, there was a cohort-related decrease in worries about social problems; however, there was little change in the importance of religion or the role that status plays on accomplishment.

Summary of Cohort Differences. Using the cutoff of .10 for the correlation between cohort and attribute, we can generate a picture of generational changes in the thoughts, feelings, and behaviors that we evaluated in this article. Out of the 31 variables that we considered, 9 passed our threshold for consideration as at least a small effect size (to be sure, none reached our threshold for consideration of a medium effect size; i.e., none were larger than .25). In particular, members of more recent cohorts were less trusting of others and more cynical of institutions. Members of more recent cohorts tended to have higher and perhaps unrealistic expectations for their future and seemed less convinced that working hard will lead to desired jobs. They expressed less interest in keeping up with materialistic trends; however, at the same time they were more tolerant of blatant consumerism and the marketing of unnecessary material goods. There was one small curvilinear effect: The importance of having money peaked in 1990s and has declined since that time. Finally, members of more recent cohorts expressed fewer worries and concerns about social issues. 
In total, the overall pattern suggests that cohort effects, when noticeable, were fairly small. It was also the case that some of the directions of the effects ran counter to the Generation Me profile. For example, the effects for self-enhancement and self-esteem were negative (i.e., more recent cohorts had lower scores on these variables than older cohorts) and the effects for happiness and life satisfaction were positive (i.e., more recent cohorts had higher scores on these variables than older cohorts).

\section{Comparisons of Ecological and Individual Correlations. In} addition to evaluating cohort-linked changes, we were also interested in comparing the magnitude of ecological and individual correlations. Ecological correlations between year of data collection and average yearly score are displayed in the last column of Table 3 (recall that these correlations are based on 31 observations, each observation pairing the year with the cohort mean score on a construct for that year). As seen in Table 3, there were substantial differences between the size of the individual correlations and the ecological correlations. To quantify this difference, we transformed the individual and ecological correlations from $r \mathrm{~s}$ to $Z \mathrm{~s}$ and took the average of the absolute value of their difference. We then transformed the average back into the $r$ metric. The average difference was $.59(S D=.26$, minimum $=.02$, maximum $=.96)$ and the difference was .50 or larger (in the $r$ metric) for 22 out of the 31 comparisons. Thus, consistent with previous caveats regarding ecological correlations (W.S. Robinson, 1950; Rosenthal et al., 2000), we found that ecological effects were often much larger than individual correlations. In general, we concluded that ecological effects tended to exaggerate perhaps psychologically trivial effects when viewed as individual level effects.

To further illustrate this point, we evaluated how our interpretations might have changed if we applied our $r \geq .10$ decision rule to the ecological correlations for determining whether or not results were worth discussing. Under this scheme, we would have concluded that 29 out of the 31 constructs changed and many changed in very substantial ways (the average effect based on the alerting coefficient was .62). Thus, our conclusions would have been quite a bit different had we looked to ecological correlations rather than individual correlations. As such, the big lesson we drew from our analyses was that the ecological correlation was a poor indicator of the size of any cohort-linked change when the effects were considered at the level of the individual. Moreover, we found several trends were opposite to those predicted by the Generation Me hypothesis. That is, self-esteem, loneliness, materialism, and fears over social issues declined in recent cohorts whereas happiness and life satisfaction increased in recent cohorts based on the signs of the ecological correlations. These changes run counter to the general profile of Generation Me described by Twenge (2006).

However, it is important to again note that the interpretations based on the cross-temporal meta-analyses have not been solely based on the ecological correlation per se. As we noted in the introduction to this article, researchers often use the unstandardized regression equation from the "ecological analysis" to estimate scores at the end time points, which can then be converted to a $d$-metric effect size using an estimate of the individual level standard deviation. Rather than use this method, we calculated the $d$ using raw scores by comparing the first 5 years and the last 5 years of data collection. ${ }^{4}$ Conclusions based on the $d$ metric would have been similar to conclusions based on the individual level correlation; however, some differences did arise. First, many of the $d$ s were larger than the individual level correlation. Using Wolf's (1986) convention that $d=(2 \times r) / \sqrt{ }\left(1-r^{2}\right)$, we found that eight of the $d s$ were overestimates of .10 or more. Second, two $d$ s passed the threshold for a small effect size, whereas the $r$ failed to pass that threshold (i.e., contributed to charity, importance of having money). However, the $r \mathrm{~s}$ in these cases were very close to the threshold (.09). Third, one $d$ failed to pass the threshold, whereas the corresponding $r$ did (i.e., cynicism towards the government). Taken together, these results suggest that converting scores to a $d$ metric will likely result in fewer false positives than would be found using the ecological correlation; however, without access to the individual level data, it is an open question as to the precise extent of the bias when researchers estimate $d$-metric effects using the regression equations with aggregated data.

A few other comments about the $d$-metric approach are relevant. First, although previous research has shown that individual and ecological correlations can differ in sign (Rosenthal et al., 2000), in no case did we observe effects that differed in sign. Second, the unstandardized ecological beta might be the most appropriate way to report and interpret the size of the ecological effects (and thus the results of a cross-temporal meta-analysis) because these coefficients help emphasize the arbitrary nature of many of the metrics used in the cohortbased analyses and may force readers into thinking more directly about the independent and dependent variables. In other words, results reported in terms of changes in scale scores per year might be the preferred method for reporting ecological effects when the dependent variables are measured in arbitrary metrics. In addition, we question whether a translated $d$-metric approach is optimal for a continuous effect size metric, given that birth year and measures of attitudes and personality characteristics are typically both continuous variables. In general, we believe that reporting results in a continuous unstandardized metric has certain conceptual advantages over the $d$-metric approach for describing ecological effects.

\section{Discussion}

Given the potential costs of inflated descriptions of cohort differences, it is essential to evaluate the robustness of the evidence for the Generation Me profile, because such characterizations have important implications for how a generation views itself and is viewed by society at large. In general, we found little reason to conclude that the average member of Generation Me is dramatically different from members of previous generations. Today's youth seem to be no more egotistical than previous generations, and they appear to be just as 
happy and satisfied as previous generations. In fact, today's youth seem to have psychological profiles that are remarkably similar to youth from the past 30 years. However, we did find that more recent generations have higher expectations for their educational careers and are more cynical and distrusting than previous generations. Nonetheless, using the MTF data sets, we found little evidence to support deep concerns about the current generation of youth, especially in terms of their feelings of self-worth, egotism, and rates of misery (see also Trzesniewski et al., 2008a).

Many readers might find our conclusions surprising. After all, findings about Generation Me have been well cited and discussed extensively in the popular media. Moreover, most people can think of anecdotal evidence consistent with the characterization of members of Generation $\mathrm{Me}$ as egotistical, entitled, and even narcissistic. Nonetheless, a similar pattern of disconnect seems to exist between perceptions of national character and self-reports of the actual personality traits of members of those cultures (McCrae \& Terracciano, 2006; Terracciano, AbdelKhalek, et al., 2005). Quite simply, Terracciano, AbdelKhalek, et al. (2005) did not find compelling evidence that perceptions of national character matched the average personality profiles of samples of individuals taken from those cultures (but see Heine, Buchtel, \& Norenzayan, 2008).

Indeed, psychological theory suggests that great care should be exercised when forming generalizations about entire groups of people (e.g., all individuals born in a particular decade) based on limited perceptions that might be unduly influenced by extremely memorable exemplars. Such biases in judgment might explain the intensity of the belief in Generation Me. Consider again how easy it is to think of a particular young person who is egotistical or miserable or extremely lazy. This ease may simply reflect an availability bias (Tversky \& Kahneman, 1974), reflecting memorable individuals rather than the true state of affairs of the entire generation. Moreover, once a set of perceptions about Generation Me is established, a confirmation bias may set in whereby individuals selectively attend and recall pieces of information that are consistent with this stereotype. Thus, there may be psychological reasons for the beliefs about members of so-called Generation Me that have little to do with actual generational differences (for a review of social cognitive mechanisms involved in stereotype formation and maintenance, see Hamilton \& Sherman, 1994).

In particular, research has shown that people have a bias when it comes to viewing the world (and its inhabitants) as either changing or remaining the same (Eibach, Libby, \& Gilovich, 2003). For example, Eibach et al. (2003) found that when someone becomes a parent, they often start to see the world as a much more dangerous place, an understandable change considering that new parents are now typically worried about the safety of their child. Consider the experience of new parents who are driving home from the hospital with their newborn as illustrated in the comedy, Knocked Up. Traffic speeds that were once an unremarkable feature of daily life are now perceived as threatening and dangerous. The concern is that individuals sometimes mistake changes in their perception of the world for actual changes in external environment; that is, individuals misattribute changes that have occurred within themselves to changes in the world. Thus, the new parent may begin to believe that drivers are objectively more dangerous and careless when all that has really happened is that the individual assumed a new role which entails a different set of concerns, responsibilities, and perceptions related to the safety and security of his or her child. The world did not change.

Eibach et al. (2003) suggest that such a process may explain widespread perceptions of societal decline by older individuals, such as the perceived personal and moral failings of the next generation. This might be especially relevant given evidence for normative personality changes with age (e.g., on average, individuals tend to become more agreeable and conscientious during the transition to adulthood; see Caspi, Roberts, \& Shiner, 2005). It is also interesting to note that perceptions of the negative characteristics of youth have apparently existed for a considerable period of time as illustrated by the opening quote from Socrates. Thus, Eibach et al. (2003) may have identified a long-present psychological bias.

In addition, technology itself may also facilitate the impression that more recent generations are more self-absorbed or self-aggrandizing than previous generations. This can happen in at least three ways: First, media saturation provides widespread, repeated exposure to the escapades of young celebrities or participants in the contrived settings of reality TV. Although these individuals might be atypical for members of their generation, they can end up serving as salient exemplars of their generation for observers. Second, the perception that there are more entitled members of the current generation of youth may be driven by the norms of electronic communication. For example, e-mail is an impersonal and low cost way to make requests of others; thus, the number of entitled students and employees may not have changed over the years-rather technology now makes it easier for such people to make themselves noticed. Third, the popularization of Web sites like YouTube and Facebook may provide a way to introduce particularly exhibitionistic members of a generation to the wider culture. Nonetheless, it is hard to know how such online personal expression translates to offline behavior in the real world without more intense research.

Given all of these considerations, it is important to return to the issue of within-generation variability. One of the virtues of conducting analyses on raw data as opposed to collecting means and standard deviations (as is the practice in a cross-temporal meta-analysis) is that it is possible to look at the precise distributions for all variables for different time points without imposing any assumptions on this distributions. This focus can help place within-cohort variability in sharper relief. As an illustration, consider Figure 2, which was constructed by plotting the distribution of two random samples of 3,000 from the 1976 and 2006 data sets for the variables assessing expectations to graduate college (Panel A) and self-esteem (Panel B). Both panels show that there is considerable overlap in the two distributions, which is an important point given that expectations about graduating college was one of our largest effect 

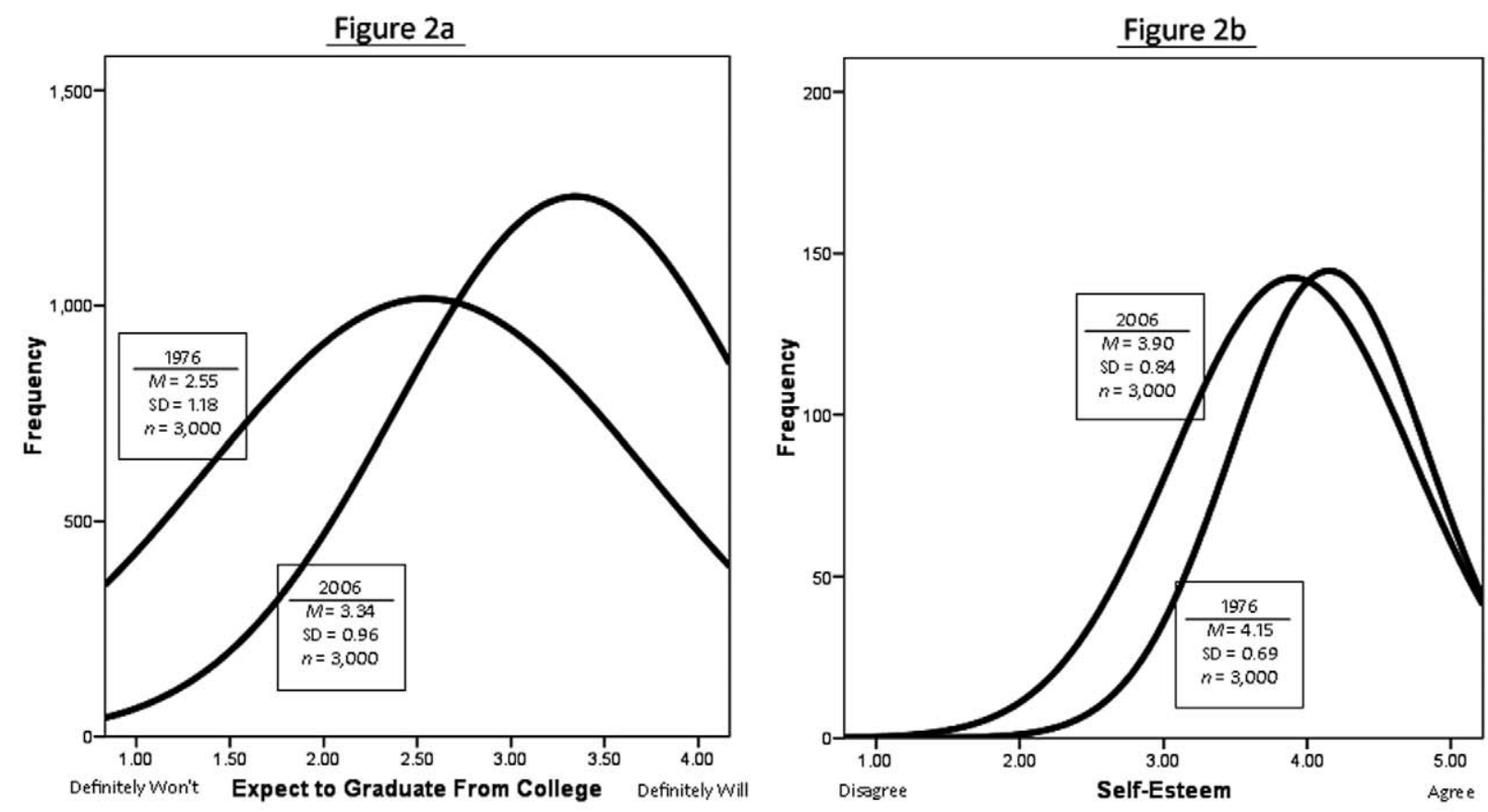

Fig. 2. Graphical representation of the distribution of 1976 and 2006 scores for expectations for graduating from college (a) and self-esteem (b).

sizes. The self-esteem distribution showed considerable overlap while also highlighting that more people had extremely low scores in 2006 than in 1976. Nonetheless, both panels illustrate the principle of variability and show that there is considerably more within-cohort variability than between-cohort variability. Thus, it appears that a majority of the 2006 youth fall within the 1976 range of scores, even for the largest difference we found (expectations to graduate college).

Although we did not find much support for large mean-level generational changes, we did find some evidence that highschool seniors in more recent years have higher expectations for their future education (see also Reynolds et al., 2006). These expectations might be increasingly unrealistic. One explanation for these changes is that individuals may expect more out of their educational careers because of grade inflation. Indeed, there appears to be some grade inflation over the past 30 years: The correlation between self-reported grades and cohort was .12. However, controlling for these reports of grades does not fully attenuate the correlation between expectations and cohort (the correlation between cohort and the expectation that an individual will graduate from college changed from .23 to .21 , whereas the correlation between cohort and the expectation of going to graduate school changed from .20 to .17). Accordingly, the grade inflation as a source of "false hopes" explanation is not well supported by these data. Moreover, as our results show, academic self-enhancement and egotism in the form of increasing perceptions of intellectual ability relative to peers have not appreciably risen over the past 30 years.

A different and perhaps more mundane explanation for the cohort-related increases in expectations is that individuals are expressing the sentiment that they need more education to secure a job that pays middle-class wages. In other words, this increase in stated expectations may reflect a more or less rational response to shifting labor market conditions in the United States. Of course, not all adolescents will go on to realize their expectations; our point is that increased expectations by themselves may not necessarily represent an increase in the narcissistic illusions of youth - such changes may actually represent perceptions of changing economic realities. A full accounting of the antecedents and consequences of the potential discrepancy between expectations for higher education and actual attainment is beyond the scope of this report; our point is that the reasons behind increasing expectations might have little to do with increasing narcissism.

In addition to changes in educational expectations, we also found evidence that more recent cohorts reported higher levels of cynicism and lower levels of trust in others; however, these effects are small in magnitude, representing a change of approximately .01 scale points per year. Nonetheless, these findings replicate work by sociologists R.V. Robinson and Jackson (2001), who also found cohort-related increases in mistrust using the General Social Survey. This increase in cynicism and decline in trust is also consistent with longitudinal work by Terracciano, McCrae, and Costa (2006), who examined personality changes in the Baltimore Longitudinal Study of Aging and found that later-born cohorts declined more in personality traits related to trust than earlier-born cohorts. Another important consideration is R.V. Robinson and Jackson's finding that trust levels have started declining in cohorts born in the mid-1940s and later. This means that declines in trust are probably not restricted to the current generation of youth and instead reflect something more universal 
about changing American attitudes. Undoubtedly, the psychological and behavioral consequences of a decline in trust are an important area for future research; the point here is that these trends don't seem to indicate that Generation Me is particularly unique when it comes to increasing levels of mistrust and cynicism.

One major limitation of our study is that our findings may have been attenuated by less-than-ideal measurements of some of the constructs of interest. That is, many of the constructs were assessed with short, seemingly face-valid scales, and measurement issues may have limited our ability to detect potential cohort effects. To be sure, most of the scales have not been validated using intensive construct validation procedures. This limitation should be balanced against the virtues of using a data set that was collected in a systematic way using probabilistic methods. This sampling method strengthens the case for generalizing to members of entire birth cohorts. This design is a notable improvement over the haphazard sampling methods that are used in most college student and child samples that make up the bulk of studies included in existing cross-temporal meta-analyses. In this regard, we believe that the sampling method used in the MTF study is inherently superior to the sampling methods that serve as the foundation for many of the existing conclusions about Generation Me. Quite simply, we do not believe that reasonable population-based inferences can be made from cross-temporal meta-analytic studies that are based on convenience samples.

Another potential limitation of the current work is that many of the findings are essentially null results. Such effects can be difficult to interpret given the adage that an absence of evidence is not evidence of an absence. On the other hand, null results can be informative when they result from statistically powerful studies and run counter to a predicted effect. Thus, we believe that the kinds of null effects that we report are scientifically meaningful. We should also point out that there are hundreds of variables in the MTF data sets and that these results are but a subset that we believed were well-matched to addressing the broad claims made about Generation Me.

Finally, we wish to emphasize that our results are also relatively consistent with other results finding no strong evidence for cohort-linked changes in some of the traits relevant to the Generation Me hypothesis. For example, McCrae and Costa (2003) failed to find cohort-linked increases in Neuroticism in the National Health and Nutrition Examination Study and concluded that "the cross-sequential analyses Twenge (2000) reports for her student samples are inconsistent with longitudinal and cross-sectional analyses of adults" (p. 80). More recently, Terracciano, McCrae, Brant, and Costa (2005) failed to find evidence for a cohort-linked increase in Neuroticism and instead even found very slight cohort-linked declines for this trait (see also Terracciano et al., 2006). Thus, there has been a failure to duplicate the results of Twenge's (2000) cross-temporal meta-analysis of Neuroticism scores.

Moreover, psychiatric studies that used well-established measures have also failed to find widespread, linear cohort changes in internalizing and externalizing problems in youth over the past decades (e.g., Achenbach, Dumenci, \& Rescorla, 2003). For example, self, teacher, and parent reports of U.S. youth symptoms (e.g., anxiety, conduct disorder, disobedience, affective problems) have changed very little from 1989 to 1999, based on nationally representative samples of children aged 11-18 (Achenbach, Dumenci, \& Rescorla, 2002). These authors concluded “... despite impressions conveyed by the media, multi-informant assessment of representative samples of youth living in the United States did not indicate worsening in terms of specific problems and competencies over the decade from 1989 to 1999" (Acenbach et al., 2002, p. 201). Likewise, a meta-analysis of epidemiological studies of depression in children and adolescence conducted over the last 30 years failed to indicate changes in depression in later-born cohorts (Costello, Erkanli, \& Angold, 2006, see also Twenge \& Nolen-Hoeksema, 2002). Collectively, this evidence counters the generalization that members of more recent birth cohorts are becoming substantially more miserable (i.e., more depressed and anxious) and may help to assure fears that our null results are simply anomalies.

All in all, these other findings along with the present results from the MTF data set converge to paint a much less dramatic picture of cohort-linked changes over the last 30 years. As such, we have tentatively concluded that concerns over the characteristics of Generation Me may not be well founded. In sum, our analyses using the MTF study cast considerable doubt on the idea that there is anything singular about the generation born in the 1970s, 1980s, and 1990s, especially in light of the considerable amount of within-cohort variability. Perhaps the more interesting psychological story concerns the persistence of beliefs about cohort-related changes when clear evidence of such effects is fairly limited and when the positive effect sizes are small by psychological standards.

\section{Notes}

1. We are referring to effects on personality and social development that are specific to a generation (e.g., psychological characteristics that are a consequence of experiencing the Great Depression at a certain age; e.g., Elder, 1974). These changes are different from "universal" age-related changes in personality that occur in every generation regardless of historical factors such as purported increases in self-control that are associated with the transition to adulthood.

2. It is useful to note that the unstandardized regression coefficient is the same for both analyses. This suggests that reporting ecological results in terms of changes in the original metric of the scale may be preferable when working with ecological effects (i.e., the data in Table 1 indicate that the average yearly score increased by .004 scale points per year between 1985 and 2000). We elaborate on this point later.

3. The results did not differ when the full six-item scale was examined from 1977 through $2006(r=-.01)$ nor when only the four-item scale was examined from 1976 through 2006 ( $r=-.04$; see also Trzesniewski \& Donnellan, 2009).

4. We elected to use this method because we felt it was more precise and reliable to use all of the raw data, especially given our ample 
sample sizes, and aggregate across several years. However, we also calculated the $d$ s based on the predicted scores for 1976 and 2006 . On average, the predicted $d$ s were .07 standardized units higher than the raw $d$ s (range $=.00-.23$, median $=.07$ ).

\section{Acknowledgments}

Both authors contributed equally. We thank Fred Oswald and Jessica Tracy for the valuable feedback on earlier drafts of this article. We would also like to thank Ashley Christian Major and Nicole Galati for their assistance with data management.

\section{Declaration of Conflicting Interests}

The authors declared no conflicts of interest with respect to the authorship and/or publication of this article.

\section{References}

Achenbach, T.M., Dumenci, L., \& Rescorla, L.A. (2002). Ten-year comparisons of problems and competencies for national samples of youth: Self, parent, and teacher reports. Journal of Emotional and Behavioral Disorders, 10, 194-203.

Achenbach, T.M., Dumenci, L., \& Rescorla, L.A. (2003). Are American children's problems still getting worse? A 23-year comparison. Journal of Abnormal Child Psychology, 31, 1-11.

Arnett, J. J. (2007). Suffering, selfish, slackers? Myths and reality about emerging adults. Journal of Youth and Adolescence, 36, 23-29.

Arnett, J.J. (in press). Storm and stress redux. American Journal of Psychology.

Bachman, J.G., Johnston, L.D., \& O’Malley, P.M. (1996). The Monitoring the Future project after 22 years: Design and procedures (Monitoring the Future Paper No. 38). Ann Arbor, MI: Institute for Social Research, University of Michigan.

Baltes, P.B. (1968). Longitudinal and cross-sectional sequences in the study of age and generation effects. Human Development, 11, 145-171.

Baltes, P.B., Cornelius, S.W., \& Nesselroade, J.R. (1979). Cohort effects in developmental psychology. In J.R. Nesselroade \& P.B. Baltes (Eds.), Longitudinal research in the study of behavior and development (pp. 61-87). New York: Academic Press.

Bell, R.Q. (1953). Convergence: An accelerated longitudinal approach. Child Development, 24, 145-152.

Bellah, R.N., Madsen, R., Sullivan, W.M., Swidler, A., \& Tipton, S.M. (1985). Habits of the heart: Individualism and commitment in American life. Berkeley: University of California Press.

Blanton, H., \& Jaccard, J. (2006). Arbitrary metrics in psychology. American Psychologist, 61, 27-41.

Bronfenbrenner, U., \& Morris, P.A. (2006). The bioecological model of human development. In W. Damon \& R.M. Lerner (Eds.), Handbook of child psychology, Vol. 1: Theoretical models of human development (6th ed., pp. 793-828). New York: Wiley.

Caspi, A. (1998). Personality development across the life course. In W. Damon (Ed.), Handbook of child psychology, Vol. 3: Social, emotional, and personality development (5th ed., pp. 311-388). New York: Wiley.

Caspi, A., Roberts, B.W., \& Shiner, R.L. (2005). Personality development: Stability and change. Annual Review of Psychology, 56, 453-484.
Cattell, R.B. (1970). Separating endogenous, exogenous, ecogenic, and epogenic component curves in developmental data. Developmental Psychology, 3, 151-162.

Cohen, J. (1988). Statistical power analysis for the behavioral sciences (2nd ed.). Hillsdale, NJ: Erlbaum.

Cooper, H., \& Patall, E.A. (2009). The relative benefits of metaanalysis conducted with individual participant data versus aggregated data. Psychological Methods, 14, 165-176.

Costa, P.T., Jr., \& McCrae, R.R. (1982). An approach to the attribution of aging, period, and cohort effects. Psychological Bulletin, 92, 238-250.

Costello, E.J., Erkanli, A., \& Anglod, A. (2006). Is there an epidemic of child or adolescent depression? Journal of Child Psychology \& Psychiatry, 47, 1263-1271.

Donaldson, G., \& Horn, J.L. (1992). Age, cohort, and time developmental muddles: Easy in practice, hard in theory. Experimental Aging Research, 18, 213-222.

Eibach, R.P., Libby, L.K., \& Gilovich, T.D. (2003). When change in the self is mistaken for change in the world. Journal of Personality and Social Psychology, 84, 917-931.

Elder, G.H., Jr. (1974). Children of the Great Depression. Chicago: University of Chicago Press.

Elder, G.H., Jr., Modell, J., \& Parke, R.D. (Eds.) (1993). Children in time and place: Developmental and historical insights. New York: Cambridge.

Elder, G.H., Jr., \& Shanahan, M.J. (2006). The life course and human development. In W. Damon \& R. M. Lerner (Eds.), Handbook of child psychology, Vol. 1: Theoretical models of human development (6th ed., pp. 665-715). New York: Wiley.

Glenn, N.D. (1976). Cohort analysts' futile quest: statistical attempts to separate age, period, and cohort effects. American Sociological Review, 41, 900-904.

Hamilton, D.L., \& Sherman, J.W. (1994). Stereotypes. In T.K. Srull \& R.S. Wyer (Eds.), Handbook of social cognition (Vol. 2, 2nd ed., pp. 1-68). Hillsdale, NJ: Erlbaum.

Heine, S.J., Buchtel, E., \& Norenzayan, A. (2008). What do crossnational comparisons of personality traits tell us? The case of conscientiousness. Psychological Science, 19, 309-313.

Helson, R., Kwan, V.S.Y., John, O.P., \& Jones, C. (2002). The growing evidence for personality change in adulthood. Findings from research with personality inventories. Journal of Research in Personality, 36, 287-306.

Hemphill, J.F. (2003). Interpreting the magnitudes of correlation coefficients. American Psychologist, 58, 78-79.

Hyde, J.S. (2005). The gender similarities hypothesis. American Psychologist, 60, 581-592.

Johnston, L.D., Bachman, J.G., \& O’Malley, P.M. (2003). Monitoring the future: A continuing study of the lifestyles and values of youth. Ann Arbor, MI: Inter-University Consortium for Political and Social Research.

Johnston, L.D., O’Malley, P.M., Schulenberg, J.E., \& Bachman, J.G. (1998). The aims and objectives of the Monitoring the Future study and progress toward fulfilling them (2nd ed., Monitoring the Future Occasional Paper No. 34). Ann Arbor, MI: Institute for Social Research, University of Michigan.

Judge, T.A., Erez, A., Bono, J.E., \& Thoresen, C.J. (2002). Are measures of self-esteem, neuroticism, locus of control, and generalized 
self-efficacy indicators of a common core construct? Journal of Personality and Social Psychology, 83, 693-710.

Kline, R.B. (2004). Beyond significance testing: Reforming data analysis methods in behavioral research. Washington, DC: American Psychological Association.

Kosloski, K. (1986). Isolating age, period, and cohort effects in developmental research: A critical review. Research on Aging, 8, 460-479.

Kuncel, N.R., Credé, M., \& Thomas, L.L. (2005). The validity of selfreported grade point averages, class ranks, and test scores: A metaanalysis and review of the literature. Review of Educational Research, 75, 63-82.

Lasch, C. (1979). The culture of narcissism: American life in an age of diminishing expectations. New York: Norton.

McCrae, R.R. \& Costa, P.T., Jr. (2003). Personality in adulthood: A five-factor theory perspective (2nd ed.). New York: Guilford Press.

McCrae, R.R., \& Terracciano, A. (2006). National character and personality. Current Directions in Psychological Science, 15, 156-161.

Navarrette, R. (2008, June 28). Parenting affects borders. Lansing State Journal, p. 4A.

Nesselroade, J.R., \& Baltes, P.B. (1974). Adolescent personality development and historical change: 1970-1972. Monographs of the Society for Research in Child Development, 39, 1-80.

O’Mara, A.J., Marsh, H.W. Craven, R.G., \& Debus, R.L. (2006). Do self-concept interventions make a difference? A synergistic blend of construct validation and meta-analysis. Educational Psychologist, 41, 181-206.

Pedhazur, E.J., \& Schmelkin, L.P. (1991). Measurement, design, and analysis: An integrated approach. Hillsdale, NJ: Erlbaum.

Prentice, D.A., \& Miller, D.T. (1992). When small effects are impressive. Psychological Bulletin, 112, 160-164.

Putnam, R.D. (2000). Bowling alone: The collapse and revival of American community. New York: Simon \& Schuster.

Raskin, R., \& Terry, H. (1988). A principal-components analysis of the Narcissistic Personality Inventory. Journal of Personality and Social Psychology, 54, 890-902.

Reynolds, J., Stewart, M., MacDonald, R., \& Sischo, L. (2006). Have adolescents become too ambitious? High school seniors' educational and occupational plans, 1976 to 2000. Social Problems, 53, 186-206.

Richard, F.D., Bond, C.F., Jr., \& Stokes-Zoota, J.J. (2003). One hundred years of social psychology quantitatively described. Review of General Psychology, 7, 331-363.

Roberts, B.W., \& Helson, R. (1997). Changes in culture, changes in personality: The influence of individualism in a longitudinal study of women. Journal of Personality and Social Psychology, 72, 641-651.

Roberts, B.W., Kuncel, N.R., Shiner, R., Caspi, A., \& Goldberg, L.R. (2007). The power of personality: The comparative validity of personality traits, socio-economic status, and cognitive ability for predicting important life outcomes. Perspectives on Psychological Science, 2, 313-345.

Robinson, R.V., \& Jackson, E.F. (2001). Is trust in others declining in America? An age-period-cohort analysis. Social Science Research, 30, 117-145.
Robinson, W.S. (1950). Ecological correlations and the behavior of individuals. American Sociological Review, 15, 351-357.

Rosenberg, M. (1965). Society and the adolescent self-image. Princeton, NJ: Princeton University Press.

Rosenthal, R. (1990). How are we doing in soft psychology? American Psychologist, 45, 775-777.

Rosenthal, R., Rosnow, R.L., \& Rubin, D.B. (2000). Contrasts and effect sizes in behavioral research: A correlational approach. New York: Cambridge University Press.

Schaie, K.W. (1965). A general model for the study of developmental problems. Psychological Bulletin, 64, 92-107.

Stewart, A.J., \& Healy, J.M., Jr. (1989). Linking individual development and social changes. American Psychologist, 44, 30-42.

Terracciano, A., Abdel-Khalek, A.M., Ádám, N., Adamovová, L., Ahn, C.-K., Ahn, H.-N., et al. (2005). National character does not reflect personality trait levels in 49 cultures. Science, 310 , 96-100.

Terracciano, A., McCrae, R.R., Brant, L.J., \& Costa, P.T. Jr. (2005). Hierarchical linear modeling analyses of the NEO-PI-R scales in the Baltimore Longitudinal Study of Aging. Psychology and Aging, 20, 493-506.

Terracciano, A., McCrae, R.R., \& Costa, P.T., Jr. (2006). Longitudinal trajectories in Guilford-Zimmerman Temperament Survey data: Results from the Baltimore Longitudinal Study of Aging. Journal of Gerontology: Psychological Sciences, 61B, P108-P116.

Textor, K. (Producer). (2008, May 23). The "Millennials" are coming. 60 Minutes. Retrieved June 29, 2008, from http://www. cbsnews.com/stories/2007/11/08/60minutes/main3475200.shtml

Trzesniewski, K.H., \& Donnellan, M.B. (2009). Reevaluating the evidence for increasing self-views among high school students: More evidence for consistency across generations (1976-2006). Psychological Science, 20, 920-922.

Trzesniewski, K.H., Donnellan, M.B., \& Robins, R.W. (2008a). Do today's young people really think they are so extraordinary? An examination of secular changes in narcissism and selfenhancement. Psychological Science, 19, 181-188.

Trzesniewski, K.H., Donnellan, M.B., \& Robins, R.W. (2008b). Is "Generation Me" really more narcissistic than previous generations? Journal of Personality, 76, 902-918.

Tversky, A., \& Kahneman, D. (1974). Judgment under uncertainty: Heuristics and biases. Science, 185, 1124-1131.

Twenge, J.M. (2000). The age of anxiety? Birth cohort change in anxiety and neuroticism, 1952-1993. Journal of Personality and Social Psychology, 79, 1007-1021.

Twenge, J.M. (2006). Generation Me: Why today's young Americans are more confident, assertive, entitled-and more miserable than ever before. New York: Free Press.

Twenge, J.M. (2008). Generation Me: The origins of birth cohort differences in personality traits, and cross-temporal metaanalysis. Social and Personality Psychology Compass, 2/3, 1440-1454.

Twenge, J.M., \& Campbell, W.K. (2001). Age and birth cohort differences in self-esteem: A cross-temporal meta-analysis. Personality and Social Psychology Review, 5, 321-344. 
Twenge, J.M., \& Im, C. (2007). Changes in the need for social approval, 1958-2001. Journal of Research in Personality, 41, 171-189.

Twenge, J.M., Konrath, S., Foster, J.D., Campbell, W.K., \& Bushman, B.J. (2008). Egos inflating over time: A crosstemporal meta-analysis of the Narcissistic Personality Inventory. Journal of Personality, 76, 875-901.

Twenge, J.M., \& Nolen-Hoeksema, S. (2002). Age, gender, race, socioeconomic status, and birth cohort differences on the
Children's Depression Inventory: A meta-analysis. Journal of Abnormal Psychology, 111, 578-588.

Twenge, J.M., Zhang, L., \& Im, C. (2004). It's beyond my control: A cross-temporal meta-analysis of increasing externality in Locus of Control, 1960-2002. Personality and Social Psychology Review, 8, 308-319.

Wolf, F.M. (1986). Meta-analysis: Quantitative methods for research synthesis (Quantitative Applications in the Social Sciences, No. 59). Beverly Hills, CA: Sage. 